\title{
UMA PROPOSIÇÃO SISTEMMICA PARA O DESENVOLVIMENTO DE EMBALAGENS
}

\author{
Rubens da Costa Santos \\ Professor do Departamento de Mercadologia da EAESP/ \\ FGV e Consultor em Marketing Industrial. \\ Virgínia Maria Ferraz de Castro \\ Mestre e Doutoranda em Saúde Pública - FSP/USP - e \\ Consultora em Marketing Nutricional e Tecnologia.
}

RESUMO: O presente trabalho propõe um enfoque sistêmico para o desenvolvimento de embalagens de alimentos. A aplicação dessa abordagem possibilitará o aprimoramento das inúmeras funções desempenhadas por esse veículo de comunicação. O reconhecimento das relações interdependentes entre os agentes presentes no sistema conduzirá ao fortalecimento da cadeia de escolha/aquisição/consumo. Com o ambiente da globalização empresarial, a proposição trará contribuições relevantes, principalmente para o setor executivo. Produtores e consumidores poderão atuar num regime de parceria, na produção e comercialização de produtos alimentícios.

ABSTRACT: This work presents a systemic view of the development of food packaging. It considers the package as a meaningful vehicle of communication during the process of commercialization. The proposed systemic approach has demonstrated to be helpful for recognition of eventual gaps in the communication process. Briefly stated the systemic approach for package development might contribute to facilitate the partnership process between entrepreneurs and consumers. Following the proposed approach a professional team work of different managerial functions can produce a package that will better communicate with the consumers of a product.

PALAVRAS-CHAVE: abordagem sistêmica, embalagem de alimentos, produtor, consumidor, comercialização.

KEY WORDS: systemic approach, food packaging, entrepreneurs, consumer, commercialization. 
A embalagem de alimentos pode ser considerada um influente veículo de comunicação, isto é, o elo de ligação entre os agentes produtor e consumidor. A embalagem vem acompanhando, rapidamente, as exigências determinadas pelo mercado consumidor, ao desempenhar vários papéis que transcendem aqueles com a finalidade de proteger, promover, transportar e/ou identificar um produto. Atualmente, nos canais de distribuição denominados de auto-serviço são encontrados diversos tipos de embalagem, para facilitar o armazenamento, a reposição e a disposição dos produtos nas gôndolas, atender às exigências do público consumidor, no tocante à oferta de unidades de consumo, e causar um impacto visual atraente e integrado ao cenário do ponto-de-venda.'

A complexidade das necessidades da sociedade, a preocupação com os problemas sociais, ${ }^{2}$ associados aos descritores nos rótulos, indicando porção de consumo, percentual e gramagem das recomendações nutricionais, ${ }^{3}$ enfatiza que a embalagem de alimentos, através da sua linguagem, procura desempenhar, também, o papel educativo, no sentido de apresentar informações voltadas para os interesses relativos à saúde pública.

Considerando-se os assuntos da década de 90 , que compreendem os conceitos de globalização, meio ambiente e o aumento da competitividade, visualiza-se um impacto direto na forma como as empresas comercializarão os seus produtos através da embalagem. ${ }^{4}$ No sentido de contribuir para o fortalecimento da comunicação entre produtores e consumidores, sugere-se o emprego da abordagem sistêmica ${ }^{5}$ para a embalagem de alimentos. Com essa abordagem, identificar-se-ão as relações de interdependência existentes entre os agentes normativos, produtivos, mercadológicos e de consumo presentes no processo da comercialização.

\section{A EMBALAGEM NO PROCESSO DA COMERCIALIZAÇÃO}

\section{Evolução histórica da embalagem e sua participação na economia de mercado}

A embalagem conquistou seu marco histórico a partir do momento em que o homem começou a produzir e comercializar seus produtos e a distingui-los dos produtos dos concorrentes, adotando o emprego de insígnias ou marcas. ${ }^{6}$

O surgimento dos canais de distribuição do tipo auto-serviço passou a exigir da embalagem certa padronização na apresentação, no tamanho adequado às dimensões das gôndolas, na aparência e na proteção quanto à integridade do produto. ${ }^{7}$ Segundo Parcels apud Gershman, ${ }^{8}$ a embalagem é um elemento que tem a faculdade de posicionar o produto para enfrentar concorrentes, estabelecer segmentos de consumidores, criar ou reforçar a imagem do produto, aumentar o lucro, a distribuição, a linha de produtos ou para avaliar o impacto de um bem no mercado de consumo. Portanto, é o fator que proporciona a diferença entre vários produtos da mesma categoria, permitindo uma competitiva participação no mercado entre os diversos concorrentes.

Segundo as estatísticas registradas no ano de 1993, a produção geral de embalagens dos gêneros alimentícios apresentou um aumento em torno de 5 a $6 \% .{ }^{9}$ Conforme matéria publicada na revista Embanews (1994), o mercado brasileiro de embalagem produziu em 1992 cerca de 3,7 milhões de toneladas, o equivalente a 5.325 milhões de dólares. Esses dados representam um valor aproximado de $1,5 \%$ do PIB - Produto Interno Bruto. De acordo com os dados publicados em uma edição especial da revista Embanews Guia de Embalagem, ${ }^{10}$ a indústria alimentícia absorve cerca de $60 \%$ de toda a produção de embalagens, gerando uma diversidade muito grande de invólucros, como latas, caixas de papelão e de cartão, recipientes plásticos e de vidro, embalagens múltiplas, cartonadas e industriais.

Conclui-se, portanto, que o setor de embalagem tem um papel de destaque no segmento de alimentos. É através dele que a indústria alimentícia pode decodificar as necessidades e os desejos do consumidor e criar, assim, novas e significativas oportunidades para o próprio setor alimentício.
1. TSUMORI, Elza. A embalagem como merchandising. SuperHiper. v.20, n.3, p. 48-52, 1994.

2. DANIELS, P. N. Reaching out to all America: coordinated nutrition education across USDA programs. J Nutr. v.124, n.9, p.1823-7, 1994.

3. LEWIS, C. J., YETLEY, E. A. Focus group sessions on formats of nutrition labels. $J$ Am Diet Assoc. v.92, n.1, p.62-6, 1992.

4. SELAME, Joe. A embalagem do futuro. F \& C Embalagem. v.6, n.61, p.66, 1993.

5. CASTRO, Virgínia M. F. Visão sistêmica da embalagem de alimentos no processo da comunicação: um estudo exploratório sobre a visão empresarial e a do consumidor. São Paulo, 1994. [Dissertação de Mestrado - Faculdade de Saúde Pública da USP.]

6. GIORGIO ZECCHINI, Rag. A evolução do conceito da embalagem. Embalagem. v.8, abr. 1975.

7. BOUVIER, Adriana S. A embalagem desde sempre. Alimentos \& Bebidas. v.1, p.15-31, abr./mai. 1989.

8. GERSHMAN, Michael. Packaging positioning tool of the $1980 \mathrm{~s}$ Management Review. v.76, p.36-8, 1987

9. OLIVEIRA, Paulo de. Balanço semestral do setor. Alimentos \& Tecnologia. v.4, ก.47, p.38-42, 1993.

10. GUIA de embalagem - Brasil 1995 Embanews. 1995, p.16, 38-9. (Edição Especial). 


\section{Aspectos conceituais e funções da embalagem}

A embalagem é destacada como uma das influentes peças promocionais sobre o comportamento do consumidor, em relação à tomada de decisão pela aquisição ou não de um bem. Por intermédio desse veículo de comunicação, o produto adquire identidade própria. A embalagem confere ao conteúdo uma personalidade que representa a imagem do produto, de forma condizente com seu posicionamento no mercado. ${ }^{11}$

A utilização adequada dos elementos que compõem a estrutura da embalagem, ou seja, a relação entre formato, contorno, material e a impressão tátil, fazem da embalagem uma ponte, um elo de ligação com o produto. ${ }^{12}$ Esse autor considera a embalagem um elemento motivador de emoções, pois, apesar de ser atraído pela aparência física externa (beleza e estética), o consumidor também procura obter certo grau de satisfação ao analisar o interior da embalagem.

Cabe enfatizar as funções básicas que estão relacionadas à proteção física do conteúdo durante as fases que incluem o período de armazenagem, transporte e manuseio do produto, ao suprimento físico das unidades de consumo, viabilizando o processo da comercialização, bem como àquelas voltadas, especificamente, para o sistema de troca e venda. Pois, com o surgimento dos supermercados como um dos mais importantes canais de distribuição do tipo autoserviço, a embalagem adquire o papel de vendedor silencioso, ${ }^{13}$ associado à função de troca. As informações contidas nas embalagens passam a funcionar como um veículo de promoção e de venda dos produtos, além de servir, informar e educar o consumidor. ${ }^{14}$

Ressalta-se, também, os importantes problemas relacionados às atividades da rotulagem e sua relevância no processo de informação/aprendizagem. Ao detalhar, cuidadosamente, os aspectos (nutricionais, os alertas às notas explicativas etc.) que devem estar presentes nos rótulos das embalagens, fica reconhecida a sua importância como eficiente e econômica medida de educação e proteção do consumidor, que está à disposição da indústria e do governo para o desenvolvimento de programas educativos. ${ }^{15}$

As funções da embalagem descritas anteriormente só se tornam possíveis a partir da sua finalidade de embalar propriamente dita, ou seja, a de conter, guardar, armazenar o produto, desde a fase de produção até o momento de seu uso pelo consumidor final. ${ }^{16}$ Conclui-se que o encadeamento desses aspectos representa, atualmente, a visão empresarial sobre a embalagem de alimentos em especial.

\section{Dinâmica no setor de alimentos}

Historicamente, constatou-se que a indústria de alimentos apresenta significativa relevância no contexto da indústria de transformação. ${ }^{17}$ A partir da década de 70 , nota-se dinâmica modernização da indústria de alimentos, que coloca à disposição do consumidor uma diversificada gama de novos produtos. Nos dias atuais, os alimentos industrializados se destacam e passam a ganhar crescente participação na dieta do consumidor. ${ }^{18}$

É patente a missão desempenhada pela indústria de alimentos na cadeia agroindustrial. Cabe ao profissional de marketing identificar as necessidades do consumidor e traduzi-las, mesmo que parcialmente, para uma linguagem organizada e ao alcance do entendimento do consumidor, tornando mais efetivo o processo da comercialização dos produtos alimentícios. Essas informações poderão oferecer novas oportunidades para o próprio setor alimentício, bem como servir como importante ferramenta para os responsáveis pela cadeia agroindustrial, mais distantes do consumidor final.

Com essa caracterização do setor de embalagem de alimentos, evidenciou-se o influente papel que esse veículo desempenha como elo de ligação na comunicação entre produtor e consumidor. É por seu intermédio que a indústria de alimentos alcança novos e mais exigentes centros de consumo e enfrenta uma recente e acirrada concorrência internacional. 


\section{Embalagem de alimentos $e 0$ comportamento do consumidor}

A embalagem de alimentos, através do seu conteúdo informativo, transmite mensagens que podem desencadear reações no comportamento do consumidor, em relação à satisfação de suas necessidades e desejos. O emprego de todos os elementos componentes da embalagem, ao dar sustentação ao produto e ao complementar sua imagem criada pela propaganda, pode conduzir ao reconhecimento de um produto e a sua venda por impulso. ${ }^{19} \mathrm{Como}$ desfecho da cadeia escolha/aquisição/consumo, o não-atendimento às expectativas do consumidor pode propiciar a chamada dissonância cognitiva ${ }^{20}$ Por exemplo, por ocasião do lançamento dos produtos dietéticos, verificou-se uma fragilidade de entendimento sobre o conceito diet (uma variação do termo dietético) entre a linguagem empregada nas embalagens $e$ as expectativas do consumidor.

A troca de mensagem entre produtor/produto/consumidor, via embalagem, permitirá a formação de novos conceitos e significados, que podem dar origem a reações positivas, caso o conjunto de informações contidas nas embalagens se apresente de maneira clara, objetiva e ao alcance do entendimento do consumidor. ${ }^{21}$ Por outro lado, podem surgir reações negativas se a linguagem empregada não conseguir retratar com fidelidade seu conteúdo, dificultando a identificação do consumidor com o produto.

Através dos anos, nota-se claramente que o comportamento da população vem assumindo aspectos e significados mais complexos, o que permite o surgimento de um segmento inovador, capaz de apresentar uma visão global, com relação a uma associação entre estado físico-mental e um dado estilo de vida. ${ }^{22} \mathrm{Com}$ essa tendência de comportamento, identificase a percepção do consumidor norte-americano relativamente à saúde $\mathrm{e}$ aos aspectos nutricionais, bem como ao estilo de vida adotado. ${ }^{23}$

O consumidor norte-americano, de um modo geral, mostra-se consciente quanto aos riscos existentes na ingestão de gordura $\mathrm{e}$ ao surgimento de doenças crônicas (coronarianas etc.). ${ }^{24}$ Entretanto, observou-se que esse consumidor sente dificuldade em aplicar as informações nutricionais contidas nos rótulos das embalagens de alimentos no momento de adotar uma dieta que atenda às recomendações nutricionais, segundo os parâmetros do "Guia da Pirâmide de Alimentos". ${ }^{25}$
Quanto ao comportamento do consumidor brasileiro, a realização de pesquisas, ${ }^{26}$ a observação de profissionais na área da elaboração de embalagens, bem como daqueles que trabalham com a atenção voltada para o campo da publicidade, vêm evidenciando uma dinâmica relativa no comportamento desse consumidor. Nota-se a adoção de estratégias que possam garantir a plena satisfação de suas necessidades, a busca por maiores informações relacionadas à qualidade dos produtos que consome, bem como a preocupação com o conteúdo da mensagem, dos signos e símbolos impressos nas embalagens de alimentos. ${ }^{27}$

A maneira pela qual é veiculada a informação de atributos do produto permite que o consumidor possa fazer sua escolha com maior segurança. $\mathrm{O}$ melhor conhecimento do consumidor permite descobrir outros elementos importantes do processo, bem como visualizar o sistema organizacional que estabelece as relações entre as diferentes partes do processo para bem poder avaliar as possíveis alterações necessárias que funcionam em benefício de um bom desempenho do mercado.

\section{VISÃO SISTÊMICA DO SETOR DE EMBALAGEM DE ALIMENTOS}

\section{Conceito sistêmico}

Para conceituar um sistema, buscou-se respaldo em estudiosos nesse campo, como Bertalanffy, ${ }^{28}$ um expoente no campo das ciências aplicadas e o criador da "Teoria Geral dos Sistemas", O'Shaughnessy ${ }^{29}$ e Johnson, Kast e Rosenweig apud Chaves. ${ }^{30}$ Segundo esses estudiosos, sistema vem a ser um conjunto de partes ou elementos interdependentes (diversificadas relações entre si) em um determinado ambiente e que forma um todo unitário.

A visão sistêmica também contribui para que o observador atento, ao analisar a dinâmica existente entre os elementos interligados de um sistema, veja novas perspectivas que conduzam ao equilíbrio, ao estado de menor tensão.

\section{A embalagem como sistema de comunicação}

A embalagem pode ser compreendida como um veículo capaz de organizar um sistema de comunicações, pois tem a faculdade de produzir informações (inputs), que são, posteriormente, transformadas em decisões
19. ROOK, Dennis $W$. The buying impulse. Journal of Consumer Research. v.14, p.189-99, 1987.

20. BENNETT, Peter D., KASSARJIAN, Harold $\mathrm{H}$. O comportamento do consumidor. São Paulo: Atlas, 1975.

21. DIAZ BORDENAVE, J. E. Além dos meios e mensagens: introduçăo à comunicação como processo, tecnologia sistema e ciência. 3.ed. Petrópolis: Vozes, 1986.

22. SANTOS, Rubens da C. Tendência de consumo de alimentos. São Paulo, Fundação Instituto Administração/USP, 1991. (Pensa: Série Temas para Discussão.) p.1-7.

23. BEAGLEY, Karen. Packaging's first: our exclusive consumer. Packaging, p.28-59 June 1985.

24. CASTELLANO, Nadine M., BALASUBRAMANIAN, Siva K., COLE, Catherine Special session - Summary consumer behavior research and its implication for product/nutritional information programs. Advances in Consumer Research. v.19 p.489-90, 1992.

25. FOOD guide pyramid replaces the basic 4 cicle. Food Technology. v. 46, n.7, p.64$7,1992$.

26. SIMAS, Fernando M., MARANGONI, N. First research on packaging and consumption: a joint project from DIL Consultants in Design and Marketing Communications and Research International. In: World Conference on Packaging, 8, São Paulo, 1993. Proceedings. Campinas, CETEA-ITAL/ IAPRI, 1993. v.1, p.78-102.

27. FIORI, Margareth. 0 consumidor do futuro-pesquisa Rhodia-FEAUSP. Diário do Comércio e Indústria, 12 dez. 1990. Seção Propaganda \& Marketing, p.11.

28. BERTALANFFY, Ludwig Von. Os progressos realizados na teoria geral dos sistemas. In:_. Te oria geral dos sistemas. 3.ed. Petrópolis: Vozes, 1977.

29. O'SHAUGHNESSY, John. Abordagem dos sistemas: definição de sistemas. In: Organização de empresas. 2.ed. São Paulo: Atlas, 1973.

30. CHAVES, Mário M. Saúde e sistemas. 3.ed. Rio de Janeiro: FGVM R. Kellogg Foundation, 1980. 
(outputs). A embalagem, sendo configurada como um sistema aberto de comunicação, pode ser considerada um subsistema do nosso sistema socioeconômico, pois representa a existência do produto, indispensável na cadeia de consumo contemporâneo. ${ }^{31}$

A realização da abordagem sistêmica permite identificar a interdependência entre os elementos componentes na embalagem, bem como as complexas relações existentes entre as partes do sistema. O conhecimento das relações de interdependência entre os vários agentes presentes no sistema propicia a união de produtores e consumidores num regime de parceria, na produção e comercialização de produtos alimentícios. Por intermédio da atuação do profissional de marketing, a embalagem passa a funcionar como o elo de ligação entre os interesses da empresa (ambiente interno) e dos consumidores (ambiente externo). O Quadro 1 apresenta graficamente as considerações formuladas anteriormente.

\section{Modelo sistêmico da embalagem de alimentos}

A embalagem de alimentos, como elemento propulsor da comunicação, exerce influência sobre o comportamento do consumidor. A complexidade do assunto decorre da troca estabelecida entre o conjunto de fatores interligados e característicos da embalagem e o meio ambiente. Determina-se a produção de uma certa integração ou unidade entre as partes envolvidas no processo, com a transmissão de mensagens aos vários segmentos da população.
Quadro 1 - A embalagem como sistema de comunicação aberto

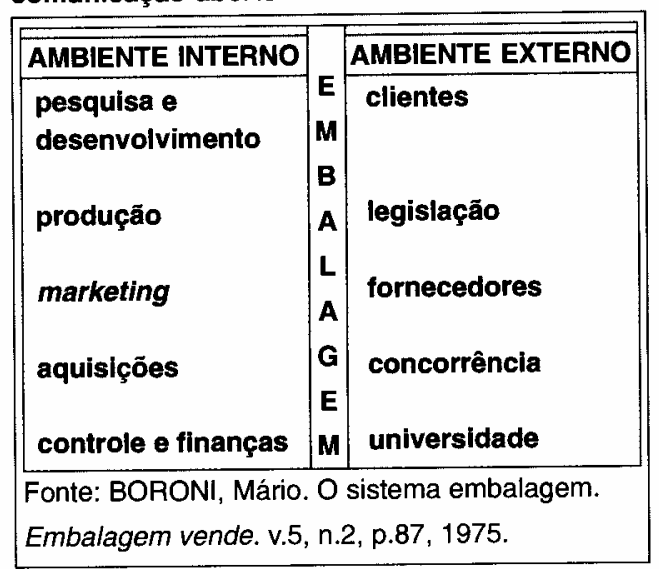

A embalagem de alimentos contém um número diversificado de informações (legais, promocionais, mercadológicas etc.), através das quais é mantido um canal de comunicação com o consumidor.

\section{a) Elementos componentes do sistema}

O papel da comunicação exercido pela embalagem apresenta significativa relação com o aspecto da sua composição. A embalagem de alimentos, por ser constituída por um número diversificado de informações, pode ser segmentada em grupos. O Quadro 2 descreve a formação de cada um dos grupos que compõem o conceito sistêmico da embalagem de alimentos. O estabelecimento do conceito sistêmico foi validado com o desenvolvimento de um estudo científico. ${ }^{32}$ Portanto, está apoiado em conteúdo literário das raras obras e estudos dedicados ao assunto em questão, bem como em exigências legais vigentes e na experiência de profissionais da área.
31. BORONI, Mário. 0 sistema embalagem. Embalagem Vende, v.2, n.5, p.84-6, 1975

32. CASTRO, Virgínia M. F. Op. Cit.

\section{Quadro 2 - A embalagem de alimentos e os elementos constituintes do conceito sistêmico}

GRUPO “ESTÉTICA"
a) Externo
- design e criatividade: o desenho e a elaboração estrutural da embalagem estão relacionados com
os avanos tecnológicos da indústria gráfica. A disposição racional/equilibrada dos elementos
- appeal/apelo visual: a atração que a embalagem pode exercer no consumidor é atentamente
observada no ambiente físico dos canais de distribuição. Esse apelo promocional não deixa de ser um
dos indutores para a compra por impulso. ${ }^{\text {b }}$
b) Interno
dinâmica e expectativa: a própria estrutura física da embalagem oferece uma noção de movimento
e gera certa expectativa. ${ }^{c}$ Refere-se ao emprego de técnicas gráficas avançadas, necessárias na
indústria alimentar, cuja norma é a busca pela diferenciação e pela sobrevivência. ${ }^{d}$




\section{GRUPO "CONVENIÊNCIA"}

- unidade de consumo: é um elemento promocional que recebe forte influência dos aspectos culturais e demográficos (constituição familiar) de determinadas sociedades, que atribuem à embalagem certo valor social, em virtude da sua praticidade de uso. ${ }^{\circ}$

- preço/visibilidade: é um dos elementos componentes do composto de marketing. Relaciona-se às estratégias de marketing adotadas para definir o posicionamento do produto no mercado. A idéia que o consumidor tem sobre preço conveniente está atrelada à imagem acerca do produto e à sua relevância no momento da compra.

- finalidade e aplicação: decorrem da definição do conceito e da composição de um produto estabelecidos por legislação própria. Influenciam-se pelo significado atribuído ao produto pelo consumidor, quanto à sua relevância em dietas alimentares, que valorizem, por exemplo, uma alimentação saudável.'

- código de barras: um fator de conveniência que contribui para a eficácia do processo da comercialização, proporciona uma linguagem padronizada, segurança no recebimento, controle de estoque e gerenciamento de preços, facilita a identificação de mercadorias e permite a comunicação computadorizada. ${ }^{9}$

\section{GRUPO "INFORMAÇÕES ESSENCIAIS"}

- composição: tem estreita relação com os aspectos legais. É a partir da menção dos ingredientes que integram os produtos que o consumidor pode iniciar um processo de escolha. ${ }^{n}$

- finalidade: a finalidade de um produto é decorrente da sua definição e apresenta forte vínculo com o aspecto legal. Por exemplo, a existência no comércio de produtos dietéticos cujo conceito não está claramente definido tem prejudicado o consumidor na escolha e emprego adequados desses produtos em dietas.

- peso/quantidade: o estabelecimento de um sistema de padronização para este item não deixa de ser a aplicação de uma medida que objetiva proteger o consumidor quando analisa alternativas oferecidas pelo mercado. Embalagens com peso ou volume padronizados facilitam a disposição e apresentação dos produtos nas gôndolas dos supermercados.

- preço/presença: está relacionado com as questões legais e com as estratégias de marketing sobre o posicionamento do produto. O preço tem reconhecida importância como elemento promocional. Conseqüentemente, é de vital importância para o funcionamento eficiente do processo de marketing. ${ }^{k}$

- marca e fabricante: mantêm estreita relação com o estabelecimento de estratégias de marketing. $A$ marca impressiona profundamente o consumidor e concorre de maneira decisiva para sua posição no mercado.'

- validade: seu estabelecimento está relacionado com as normas legais vigentes, que exigem sua presença na embalagem, a fim de que possa haver um consumo seguro dos produtos industrializados. O tempo de vida útil do produto é determinado pelo produtor.

- preparo e uso do produto: a impressão desses elementos é uma determinação legal. A sua apresentação é influenciada pela cultura de uma determinada sociedade. Os atributos do produto ficam evidenciados através de uma linguagem que está associada à prática de hábitos alimentares, bem como ao estilo de vida adotado.

\section{GRUPO "INFORMAÇÕES EDUCATIVAS"}

- integridade do produto: elemento previsto na legislação vigente. A manutenção da integridade do produto relaciona-se com o ato de protegê-lo de agressões físicas, químicas e climáticas, bem como das flutuações de temperatura no ponto-de-venda.

- reciclagem: é identificada na embalagem através de símbolos/dizeres. Relaciona-se com as medidas estratégicas de marketing ao permitir a formação de uma imagem sobre a empresa em questão quanto à possibilidade de reciclagem. 
- valor nutritivo: este elemento é importantíssimo na formação da estratégia de marketing, pois dele depende o posicionamento do produto no mercado. Seus atributos são ressaltados para diferenciá-lo dos demais que com ele concorrem no mesmo segmento de mercado.

- recomendaçōes de uso: informação educativa que decorre da aplicação de normas legais sobre a composição, finalidade e prazo de validade do produto. O formato do rótulo, por exemplo, deve ser adequado para apresentar informações, através de linguagem clara/objetiva e com uso efetivo pelo consumidor. ${ }^{m}$

\section{GRUPO "INFORMACÕES PROMOCIONAIS"}

\section{a) Permanentes}

- material/formato: esses elementos são influenciados pela evolução da indústria alimentar. ${ }^{n}$ Estão vinculados aos avanços tecnológicos e às exigências econômicas que estimulam a concorrência no mercado e que exigem do setor da embalagem um intenso dinamismo.

- preço: reforça-se, por oportuno, a sua reconhecida importância para o funcionamento eficiente do composto de marketing e por ocasião da adoção das medidas de estratégia de marketing e posicionamento do produto no mercado, como já foi mencionado anteriormente, no grupo "Informações Essenciais".

- composição: além de ser um elemento considerado essencial, seu emprego nas embalagens dos produtos alimentícios pode ser relacionado com a estratégia de marketing que se queira adotar. $\mathrm{O}$ emprego desse apelo promocional é uma forma de serem ressaltados os atributos de um produto.

- unidade de consumo: mantém forte relação com as exigências estabelecidas pelos canais de distribuição, principalmente pelos auto-serviços. Tem sido intensamente explorada a questão do valor social da embalagem, atribuído pelo consumidor, em virtude da reconhecida praticidade que ela oferece por ocasião do consumo do produto.

- marca: além de ser um elemento essencial, ressalta-se que a marca impressiona profundamente o consumidor e concorre de maneira decisiva para sua posição no mercado, conforme especificado no grupo "Informações Essenciais".

\section{b) Ocasionais}

- receitas e "dicas": a impressão desses elementos, associada ao emprego de cores e apelos visuais, revela uma estreita relação com a adoção de estratégias mercadológicas, com vistas a atingir consumidores com um perfil de comportamento diferenciado, ávidos por informações que indiquem o melhor aproveitamento do produto. ${ }^{\circ}$

- logotipo e cores: esses elementos estão intimamente ligados às estratégias de marketing adotadas. São fatores que, além de estabelecer, podem reforçar a imagem da empresa no mercado. É através do emprego de sinais que o consumidor pode atribuir um significado, uma simbologia ao produto, como ressalta Lefèvre. ${ }^{p}$

- figuras/símbolos: são elementos que representam apelos tipicamente promocionais, porém o seu emprego está vinculado às exigências legais vigentes. Matéria publicada no jornal $O$ Globo destaca a utilização de figuras ilustrativas (de frutas, por exemplo), que devem retratar com fidelidade o real conteúdo do produto nela inserido.

a. DICHTER, Ernest. Packaging: the sixth sense? A guide to identifying consumer motivation. Boston: Cahners, 1975.

b. MING, Celso. Embalagem e economia; embalagem, arte e técnica de um povo: um estudo da embalagem brasileira. Săo Paulo: Toga 1985.

c. DICHTER, Ernest. Op. Cit

d. LINNEMAM, Robert E. How to grow bigger by acting smaller.
Journal of Food Products Marketing. v.1, n.1, p.80-3, 1992

e. LARSON, Melissa. Consumer determine package success. Packaging, p.39-42, jun. 1990

ERICKSON, Greg. New trends make tood a challenging game. Packaging, p.45-8, jan. 1990

g. ASSOCIACÃO BRASILEIRA DE AUTOMAÇÃO COMERCIAL Código Nacional de Produtos Padrão - EAN: Guia de Referência n. 1. São Paulo, 1993. h. FRENCH, Warren A., BARKSDALE, Hiram C. Food labeling regulations: efforts toward dull disclosure. Journal of Marketing, v.18, p.38, 1974.

I. RIBEIRO JR., Doly, RAMOS, Solange P. A onda diet é light. Mercado Global, v.19, n.86, p.67-71, 1992

j. BOUVIER, Adriana S. A embalagem deste sempre. Alimentos \& Bebidas v.1, p.15-31, abr./mai. 1989

k LINNEMAM, Robert E. Op. Cit
B BOARIN] Margareth Os segredos que aembalagemesconde. Folha de S Pauto 6 abril 1988. Seçăo Negócios, p.1.

m. FRENCH, Warren A., BARKSDALE, Hiram C. Op. Git.

n. FARINA, Elizabeth M. M. 0., ZYLBERSZTJAN, Décio. Op. Cit.

o. BOUVIER, Adriana S. Op. Cit.

p. LEFÈVRE, Fernando. O Medicamento como mercadoria simbólica. São Paulo: Cortez, 1991. 
A Figura 1 apresenta graficamente a formação e a distribuição dos cinco grupos organizados em função de uma distribuição dinâmica existente entre os vários elementos integrantes da embalagem. Muitas vezes uma mesma variável pode estar presente, ao mesmo tempo, em mais de um grupo, dependendo da ênfase dada a ela, segundo o seu aspecto estrutural, promocional, social, legal, econômico, mercadológico e/ou educacional.

b) Alinhamento dos níveis de troca do sistema

A elaboração da embalagem de alimentos solicita a atuação de vários profissionais especializados, que buscam resolver e conciliar diversos interesses associados ao produto e a sua embalagem. Aspectos estruturais, estéticos, mercadológicos e legais precisam ser harmonizados nesse veículo de comunicação, que é a embalagem. A permuta entre os elementos constituin- tes da embalagem de alimentos mostra com clareza a existência de relações interdependentes entre os vários elementos envolvidos, que afetam a sua elaboração, bem como geram impactos no meio ambiente por ocasião do processo da comercialização dos bens de consumo. É uma situação que caracteriza o funcionamento do sistema. O Quadro 3 apresenta graficamente os elementos constituintes dos níveis intermediário e externo do "modelo sistêmico". Dando início à descrição dos níveis do sistema, levar-se-ão em consideração, inicialmente, as etapas existentes no nível intermediário.

\section{Nível intermediário}

A pesquisa e o desenvolvimento levam à análise e fomento do aperfeiçoamento de técnicas empregadas na área de produção. $O$ emprego de técnicas avançadas favorece o estabelecimento de medidas que conduzam ao posicionamento do produto no mercado.

Figura 1 - Elementos constituintes do sistema

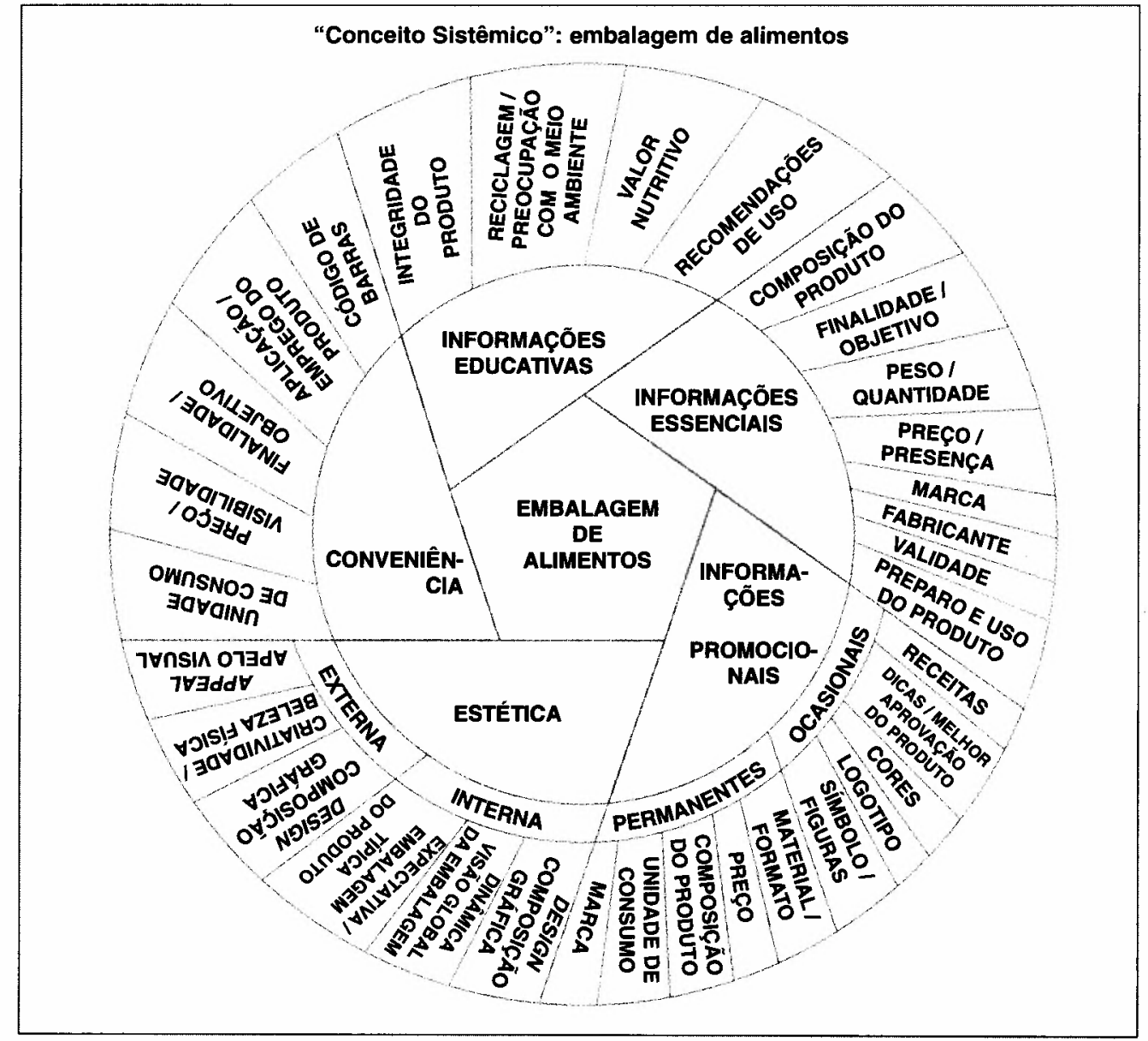

$R A E \cdot$ v. $38 \cdot$ n. $2 \cdot$ Abr./Jun. 1998 
A adoção de estratégias pela empresa, que demonstrem uma preocupação com os desejos do consumidor e as tendências do mercado a longo prazo, objetiva buscar uma posição de vantagem competitiva, seja ela mercadológica (rede de distribuição) ou tecnológica. ${ }^{33}$ Verifica-se, assim, certa correspondência entre a aplicação da tecnologia e a adoção de estratégias de marketing. A estratégia de diferenciação representa a definição por segmentos de mercado, produto, preço, bem como a promoção e distribuição da mercadoria. ${ }^{34}$

\section{Quadro 3 - Modelo sistêmico da embalagem}

de alimentos: níveis de troca do sistema

\begin{tabular}{|l|l|}
\hline \hline NíVEL INTERMEDIÁRIO & NíVEL EXTERNO \\
\hline $\begin{array}{l}\text { Tecnologia } \\
\text { área de produção e } \\
\text { P\&D: análise e fomento }\end{array}$ & $\begin{array}{l}\text { Política órgãos } \\
\text { normativos e } \\
\text { fiscalizadores }\end{array}$ \\
\hline $\begin{array}{l}\text { Estratégia Marketing/ } \\
\text { Posicionamento } \\
\text { segmento de mercado, } \\
\text { preço, produto, } \\
\text { promoção, equipe } \\
\text { vendas e distribuição }\end{array}$ & $\begin{array}{l}\text { Sociedade } \\
\text { legisladores, } \\
\text { empresas e grupos } \\
\text { sociais }\end{array}$ \\
\hline $\begin{array}{l}\text { Canais Distribuiçāo/ } \\
\text { Comercialização } \\
\text { localização área de } \\
\text { vendas, colocação na } \\
\text { gôndola e outros locais } \\
\text { de exposição }\end{array}$ & $\begin{array}{l}\text { Economia } \\
\text { demanda e } \\
\text { concorrentes } \\
\text { universidade }\end{array}$ \\
\hline $\begin{array}{l}\text { Consumidor } \\
\text { compra, preparo e } \\
\text { consumo }\end{array}$ & $\begin{array}{l}\text { Cultura } \\
\text { educação, etnia, } \\
\text { religião, demografia, } \\
\text { hábitos }\end{array}$ \\
\hline
\end{tabular}

33. FERREIRA, Antonio R. M. A indústria de embalagem no Brasil: uma abordagem de análise setorial e planejamento estratégico. São Paulo, 1992. [Dissertação de Mestrado - Escola de Administração de Empresas de São Paulo/ FGV.] p.33-4, 161-63.

34. LINNEMAM, Robert $E$. How to grow bigger by acting smaller. Journal of Food Products Marketing. v.1, n.1, p.80-3, 1992.

35. KOTLER, Philip, KAREN, F. A. F. Strategic marketing for educational institutions. New Jersey: Prentice-Hall 1985.

36. Apud FARINA, Elizabeth M. M. Q. ZYLBERSZT JAN, Décio. Op. Cit.

O emprego de figuras, símbolos e mensagens pode apontar um canal a mais de comunicação entre produtor e consumidor. A prestação de uma assistência técnica no momento em que o consumidor se dirige à empresa para sanar suas dúvidas ou sugerir alterações concretiza a aplicação de um serviço especial fornecido pelas empresas de produtos alimentícios. Além de ser o invólucro de um produto, a embalagem acondiciona valores além daqueles percebidos no próprio produto nela contido. ${ }^{35}$
A comercialização dos produtos alimentícios ocorre, principalmente, nos vários canais de distribuição do tipo autoserviço, por intermédio da embalagem. Esta última reflete um conjunto de elementos que caracteriza a sua função de venda, tais como: tamanho compatível com a prateleira/refrigeradores e estabilidade que permita o empilhamento correto, para facilitar a rotatividade de vendas e o impacto visual (aspecto harmônico no emprego de cor e de arte). A existência da inter-relação entre a estrutura física e promocional da embalagem de alimentos e sua comercialização nos vários canais de distribuição do tipo auto-serviço constitui um macropainel (técnica de reforço de imagem), que valoriza a posição da embalagem nos pontos-de-venda.

Segundo Santos, ${ }^{36}$ o conhecimento quanto ao entendimento de cada responsável da cadeia agroalimentar sobre o consumidor final é de suma importância para o funcionamento adequado do processo como um todo. O mesmo se aplica no caso dos profissionais envolvidos na elaboração da embalagem de alimentos. Nas fases de compra, preparo e consumo do produto, o consumidor busca na embalagem informações para satisfazer necessidades, desejos e expectativas. A troca estabelecida entre o consumidor e a linguagem veiculada pela embalagem de alimentos é que conduz ao fortalecimento do processo da comunicação. Como resultado final, surge a formulação de ricas informações para o aperfeiçoamento do processo de comercialização.

A seguir, far-se-ão considerações sobre as relações existentes entre a embalagem de alimentos e o nível externo, obtendo-se, assim, o alinhamento total dos níveis de troca do sistema.

\section{Nível externo}

A formulação da política pública afeta, diretamente, todas as fases de elaboração da embalagem de alimentos: uso de matéria-prima adequada, aplicação de técnicas específicas, além dos aspectos envolvidos no transporte, estocagem, distribuição e comercialização dos produtos. Dessa forma, constata-se a existência de órgãos normativos e fiscalizadores, que constituem dois grandes grupos responsáveis pela aplicação e observância das normas públicas. Aos 
órgãos normativos, que orientam o mercado, cabe a obrigação de constante atualização de seus procedimentos, a fim de que o processo se dê de maneira uniforme e disciplinada.

A existência da legislação sobre embalagem e rotulagem de alimentos visa a proporcionar o emprego de uma linguagem padronizada entre os fabricantes de alimentos e embalagens, usuários e órgãos do governo, com o objetivo de defender o consumidor. $^{37}$

O conhecimento sobre a dinâmica de mercado refere-se, também, à presença de fatores econômicos que orientam a distribuição de bens e produtos. Dentre esses fatores evidenciam-se as variáveis demanda e concorrência, que regulam a oferta de mercadorias para a comercialização. ${ }^{38}$ A linguagem empregada para apresentar e promover o produto nela inserido objetiva garantir ou ampliar a demanda. Ao mesmo tempo, pode resultar da adoção de medidas estratégicas para enfrentar os concorrentes.

Fechando o ciclo das inter-relações existentes entre a embalagem de alimentos e o nível externo do sistema, serão formuladas considerações sobre o aspecto cultural. $\mathrm{O}$ processo de decodificação da linguagem veiculada pela embalagem é influenciado por um conjunto de variáveis próprias do indivíduo (valores, religião etc.) ou relativas ao meio ambiente (classes, status social etc.). Do processamento da informação origina-se o comportamento do consumidor no mercado de consumo. $O$ emprego de uma linguagem clara e objetiva na embalagem de alimentos ajudará o consumidor a tomar decisões consideradas ideais, dentre as inúmeras alternativas disponíveis pelo processo da comercialização. ${ }^{39}$

A apresentação e promoção do bem produzido reflete a integração entre as várias fases do processo. A formulação da mensagem deve estar em consonância com os desejos, necessidades e expectativas do consumidor. Portanto, poder-se-ia dizer que o funcionamento do sistema de maneira equilibrada e harmônica deve respeitar valores, crenças, necessidades e expectativas dos indivíduos. Ao mesmo tempo, deve contar com a efetiva participação do consumidor, presente em cada uma das etapas constituintes dos níveis intermediário e externo do sistema proposto.

\section{CONCLUSÕES}

A embalagem de alimentos representa um importante e econômico instrumento de educação, em virtude de suas características. É um veículo de comunicação que, além de expressar os atributos nutritivos do alimento, sintetiza todas as etapas relativas ao complexo processo de sua produção-comercialização.

A busca por informação visando ao atendimento das exigências existentes nos diversos segmentos de mercado promove o aperfeiçoamento das operações desenvolvidas pelo setor executivo e fortalece o processo de comunicação com o consumidor. Por intermédio desse veículo de comunicação, a empresa pode manifestar a sua preocupação com a saúde dos consumidores ao colocar informações claras e objetivas e que estejam ao alcance do entendi-

A EMBALAGEM É UMA PONTE,
UM ELO DE LIGAÇAO ENTRE OS
AGENTES PRODUTOR E
CONSUMIDOR. É UM
ELEMENTO QUE TEM A
FACULDADE DE POSICIONAR O
PRODUTO.
mento do seu público-alvo - o consumidor.

A embalagem passou a ser alvo de um planejamento criterioso envolvendo vários aspectos para atender aos requisitos mercadológicos e à seleção decorrente da lei da oferta e da procura. Convém reforçar que esse mecanismo está baseado em normas legais, bem como na comunicação estabelecida com os consumidores por ocasião da decodificação da mensagem transmitida pela embalagem de alimentos.

A abordagem sistêmica para a embalagem de alimentos trará contribuições relevantes, principalmente para o setor executivo. A identificação de todos os elos do sistema subsidiará a atuação dos profissionais envolvidos no processo, bem como possibilitará a adoção de medidas que permitam uma melhor logística da embalagem durante as etapas de transporte (paletes), distribuição (display) e promoção (merchandising) do produto. Obtém-se, assim, a simplificação do processo e o barateamento do custo da produção, sem mencionar as vantagens criadas por um mecanismo eficiente, rápido e seguro na apresentação e divulgação de um produto. É através da embalagem do alimento que se dá grande parte do impacto mercadológico total do produto no consumidor.
37. BICK, Lèo F. A legislação brasileira sobre embalagem e rotulagem de alimentos. In: IV Congresso Brasileiro de Embalagem, São Paulo, 1986. São Paulo Associação Brasileira de Embalagem, 1986. p. 151

38. HOLLOWAY, Robert J., HANCOCK Robert S. Distribution systems I: channels. In: _. Marketing in a changing environment. 2.ed. New York: John Wiley \& Sons, 1973

39. ENGEL, James F., BLACKWELL, Roger D., MINIARD, Pau $W$. Alternative evaluation. In: Consumer behavior. 6.ed. Chicago: The Dryden Press, 1990. 